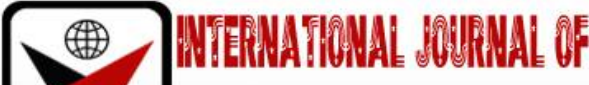

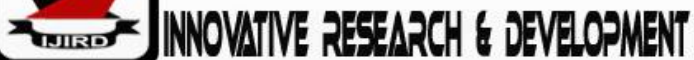

ISSN 2278 - 0211 (Online)

\section{Indigenous Knowledge Systems in Fanti Asafo Flag Designs, as Inspiration for Textile Design}

\begin{tabular}{c} 
Safo-Ankama Kweku \\
Senior Lecturer, Textile Design and Technology Department \\
Takoradi Technical University, Ghana \\
Sarah Quansah \\
Lecturer, Textile Design and Technology Department, \\
Takoradi Technical University, Ghana \\
\hline
\end{tabular}

\begin{abstract}
:
The Fanti Asafo flag images and iconography which has been adapted and used as Asafo flags for Asafo activities have been passed down over countless generations. These images serve as symbols which generate and communicate ideas, perceptions and beliefs, they are rooted in symbolism, religious practices, social taboos and totems. These symbols are visual observable fact but carry a great deal of verbal and non-verbal connotations. These images are a direct commentary on society, highlighting on all facet of human survival. The visual recognition and the message it sends is understood by its users, it is popular amongst the Fanti people of the coastal region of Ghana. They are used as motifs in the production and designing of the Asafo flag with symbolic colour for performances. This paper seeks to use the images and iconography in the Fanti Asafo flags as inspiration for textile design. The research method employed was qualitative, specifically the descriptive approach and artistic research design. The population for the study comprised the coastal dwellers from the coastal settlement across the central region of Ghana. The scope stretches from Senya Breku, Winneba, Saltpond and Cape coast. Interviews and observations were adopted for data collection. Findings revealed that images and the colour in the flags produced intricate and interesting designs that can fits perfectly into the ethnic category of textile design concepts. The usage of the images resulted in unique unconventional textile designs which can be adopted for contemporary usage in furnishing and home décor
\end{abstract}

Keywords: Coastal fanti asafo flags, asafo flags, textile design, symbols, motifs, fanti, textile design, textile design resource

\section{Introduction}

The concept of Asafo is prominent in coastal Fante culture; it shows the military strength of the community. Their presence and existence in the community ward off any war tendencies by the neighbouring communities. The Asafo culture and activities are visible during the celebration of festivals, rituals and at community ceremonies. The Asafo groups are headed by a leader who is referred to as the safohen or asafoaky3r3.This sign of authority and power of control of the safohen or asafoaky3r3 is the asafoabaa and akofena they carry. Their typical characteristics that makes Asafo visible are their unique costumes and accoutrements on display ranging from asafoabaa-whips, songs, rhythmic movements in their parades and carnivals, robust acrobatic displays showing valour and strength and usually characterised by their flags culture. The flag culture creates the unique ambience which adds colour and glamour to the celebration. The colours adopted for the flags are basically gay colour which invariably reflects the vibrant nature of the Asafo groups. A visual analysis of the flag will reveal primarily an emblem or iconography which materialise the identities of the group. The emblems and iconography depict non-tangible narratives representing the integrity and sovereignty of the state. There are also background colours that serve as the foundation that supports the iconography. The colours adopted psychologically engage the sensibilities of the group members making them more vibrant. To the viewer it creates a colourful ambience worth engaging with. Generally, the coastal Fantes have a penchant for strong bright colours. Their likeness for these colours is translated in their flag culture. Typical colours found in the Asafo flags are the reds, yellow, green, blue, orange, violet, black and the whites, basically raw colours from the artists colour tray. The flags(franka) usually come as a piece of cloth of different sizes depending on the functionality. Mostly rectangular in shape and decorated with applique technique, the iconography is mostly cut out pieces of fabrics which are affixed to the foundation fabric either by an in-laying or on-laying approach.

Their cultural and social creation which is seen as materialising social identities forms a ware house of artistic expressions. To the artist the elements and principles of art are at play unconsciously. The element of creativity which is paramount in their creations cannot be overstated. The flag culture presents rich and authentic sources of inspiration for other disciplines of artistic creations. 


\section{Literature Review}

\subsection{Motifs in Fabric Designs}

Motifs are basic recurring structures that are used in fabric design to help develop concepts to communicate major themes in a designed fabric. Motifs vary in sizes and characteristics; this is dependent on the overall outlook predetermined by the designer.

Cole (1998) is of the view that motifs as visual representation may be called icons when they achieve compelling prominence through frequent repetition in sacred and secular arts. From this view it can be noted that compelling prominence becomes a dominant concept that depicts the main theme in a designed fabric. This concept is unique with Fante flag culture where icons (imagery and totems) are adopted by groups to portray prominence of philosophies which can be communal, religious and spiritual.

Picton and Mack (1993) notes that motifs and patterns in cloth designs can be developed by two main ways, firstly, motifs and patterns produced by the actual process of fabric construction and the effect of colour variation like strips, bars, checks, and images in the case of tapestry, typical of the Ashantis and Ewes of Ghana. Secondly, motifs and patterns are produced by decorations on the surface of the cloth by painting, dyeing, printing, batik, ikat, embroidery, appliqué and others. It can be noted that the second opinion expressed by Picton and Mack which talks about motifs and patterns produced by decoration on the surface of cloth is typical with Fante Asafo flags. With this technique, imagery of mythology, spiritual, totems, images of benevolent are worked on cloth surfaces with applique, embroidery and painting techniques.

Meller and Elffers (2010) notes that motif is the most important factor in any design, determines the family to which the pattern belongs. They further stress that layout, colour also affects the orientation and total outlook of motif in pattern. These imageries which serves as motifs and typical with Fante Asafo flags puts the design into the ethnic family in the design economy in relation to textile design patterns.

\subsection{Cloth as Artistic Medium in Indigenous Performances}

In Fante cloth (tam) designs/motifs form part of the expressive quality of a performance, emotional expressiveness and attachment is intensified based on cloth, motif, colour and its relatedness to a performance. Asafo performance falls under Fante indigenous creative expressions and tam(cloth), franka(flag) gives potency to performance.

Ansu Keremeh (1998) is of the view that colour plays a part in cultural communication, they are relatively speeches free from linguistic barriers and have the advantage of the speed of impact which many others lack. It was revealed in most Ghanaian ethnic cultures that cloth motifs are affectively used as a social, religious, political and artistic medium for communication buttressing the assertion made by Ansu-Keremeh that communication can be visualized as anything that contributes a meaning of its own or any activity which is carried out by man within it cultural milieu. It was noted that motifs convey their nested thoughts of personal and societal relevance. Fante Asafo flags culture makes use of colour as a tool to communicate of sends information across to its viewers and associates. Colour association is also a way of showing allegiance, ideologies and loyalty to their symbols of benevolence. It can also be note that the flag culture and its penchant for colour as visual communicators cannot be overstated.

Cloth designs (motif and colour) in performance can stir up the concept of rivalry, statues, sorrow or victory, express belief, shows allegiance of the wearer. For example in the case of Adowa the kente cloth with intricate motif adds up to the melodic and gracefulness of the performance, the talismanic and scary embellishment of an "Obrafour" (Executioner) creates an ambience of fear and panic, the bright symbolic colours of the Fante Asafo flags during their aggressive music performances creates a charged and tension filled environment and the Ewe kente with calculated tweed effect coupled with philosophical pictorial symbols, example elephant depicting kingship, scorpion creating a mood of bitterness. These are all based on the power of indigenous imagery and indigenous psychology of colour. Cloth motifs for performances are not selected arbitrarily, because cloth design in performances is an avenue of expressiveness, it was brought to bear that its choice is closely related to the themes and purpose of the social function and performance across all ethnic lines and even secular life.

It was also realized that these designs could be enjoyed aesthetically without knowing their meanings, this was noted amongst modern appreciators looking at indigenous motifs with contemporary lenses. This to the researcher looked like a man enjoying the rhythm and instrumentation of a music without understanding the lyrics that is been communicated to the listener.

Notion of colour in cloth also served as a source of mood creation or idea communication in indigenous performances, it incorporates an active and complex system of symbolism in cloth design either religious or everyday life.

It was realized that colour in fabric gives a symbolic form, in establishing subtext for the audience to conceptualize the moment for example, joy, victory, sadness that is serving as a visual code. Basic subtext for the visual code in the Fante Asafo systems could be interpreted as follows;

fufu(white) - symbolizing sacredness, spirituality, purity, joy, hope, and victory.

Kobene (kJkJJ/memene) Red and shades of red-danger, blood, bereavement, warfare, anger, unrest, melancholy and death. 


\subsection{Symbols and Meanings of Selected Fante Asafo Flags}

The Fante Asafo flags abounds in the Fante communities because of its relevance and functionality. They are integral part of cultural endowments of the traditional community setup. The outlook of the flags presents an aesthetically colourful and philosophical ambience which attracts appreciators from all the disciplines in the art field. The indigenous knowledge systems and imageries in Fante Asafo flag designs, makes it an unexploited resource as inspiration for textile design.

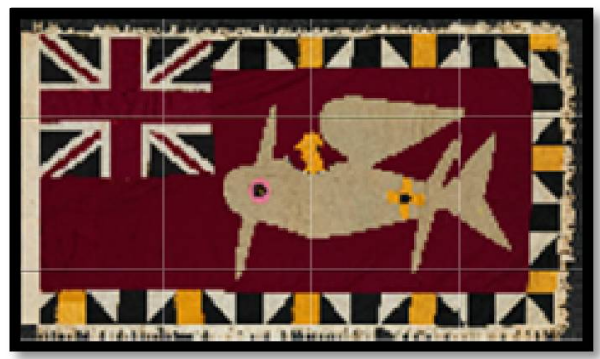

Figure 1: The Metal Bird (Plane)

The aircraft in the flag salute the ability of the owners of the flag to go anywhere without any constraints. Planes, trucks, ships and other icons in Asafo flags often occupy prominent positions on company shrines.

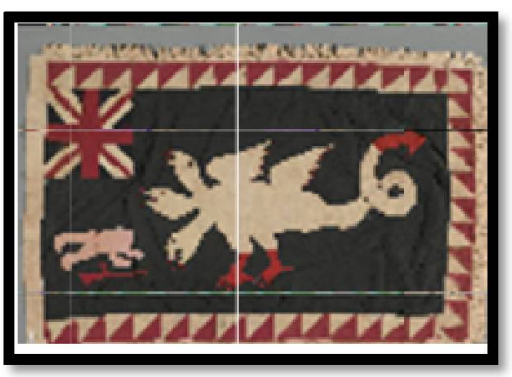

Figure 2: Three Headed Flying Monsters

The image in the field of a creature looming over a decapitated corpse suggests warning to hostile parties. The British union jack in the upper left canton served as an emblem of pride. The Fantes say this monster can "can fly, can dig in the ground and can go anywhere"

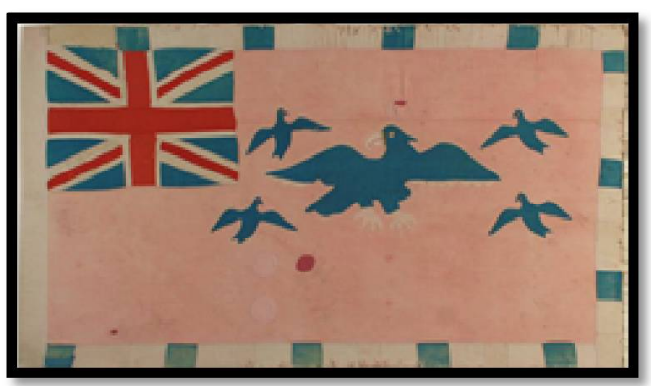

Figure 3: Flying Birds

Birds represent the presences of higher being with a connection to the sky, ultimately freeing themselves from restraints of gravity. The birds flying in the flag represent a human's ability and power to escape from his enemy and achieve success through the effort of climbing higher.

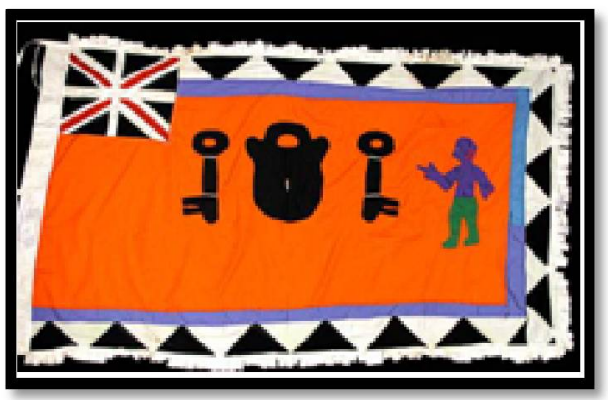

Figure 4: Communal Keys 
"Oman saafii" The key is a symbol of power and authority. It also represents freedom and liberation. A person possessing a key has the power or ability to open and unlock any door of opportunity.

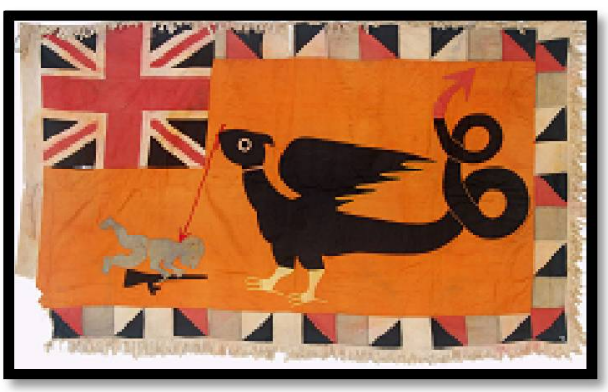

Figure 5: The Bird and the Enemy

The size of the bird being bigger than the image with a gun depicts supremacy of the Asafo company over an enemy even with a weapon in his hand.

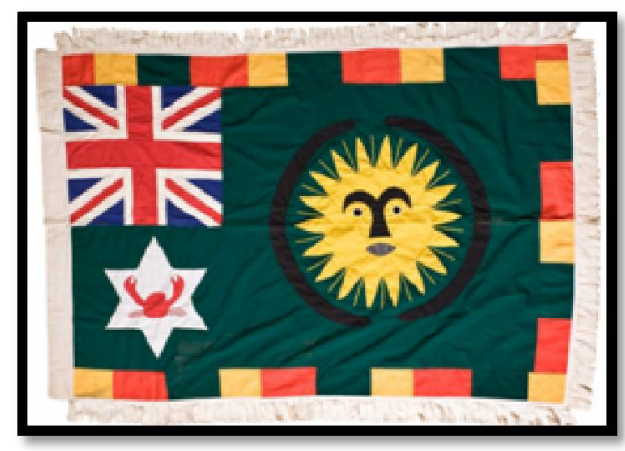

Figure 6: The Sun and the Crab

Sun and crab on star; if all the rains fall and all the stars appear and shine, but crab does not come out, no lagoon can empty it waters into the sea.

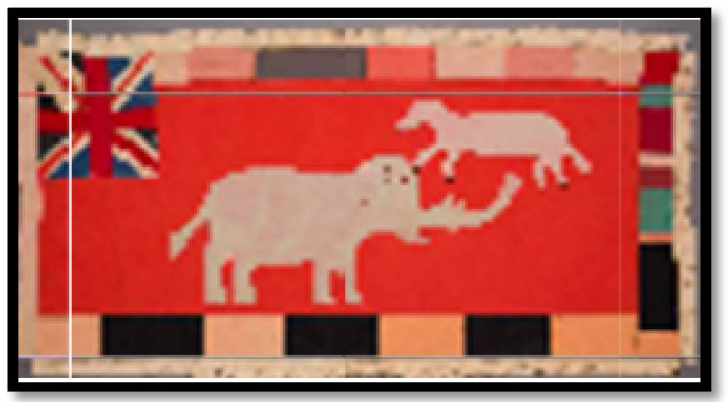

Figure 7: Elephant and the Sheep

The elephant is known as the strongest animal in the forest. The elephant in the flag therefore represent the strength and power of the Asafo company while the sheep is seen as the enemy.

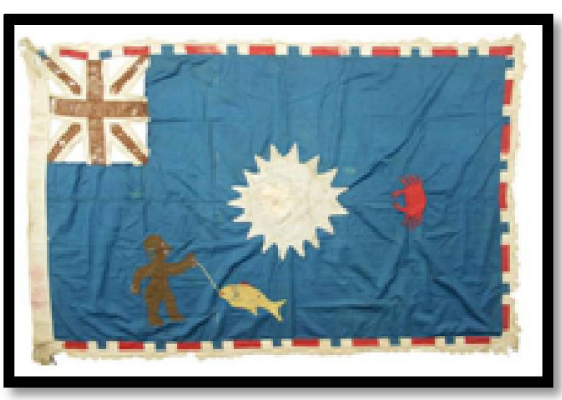

Figure 8: Crab and the Fisherman

The red crab represents the preparedness of a warrior in the diversity of this world. The sun presents energy and clearness. One can make a good catch when the coast is clear. 


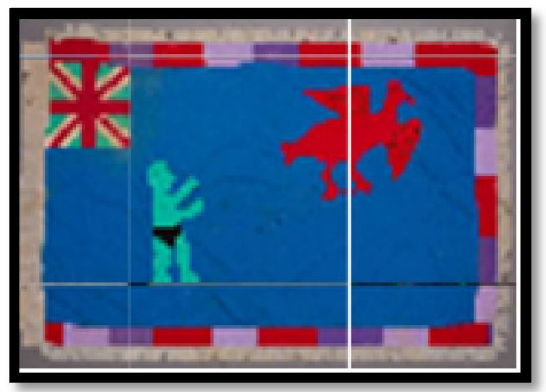

Figure 9: Enemy and Monster Bird

The bird in the flag represents an enemy who have been trapped with a rope tied around his feet.

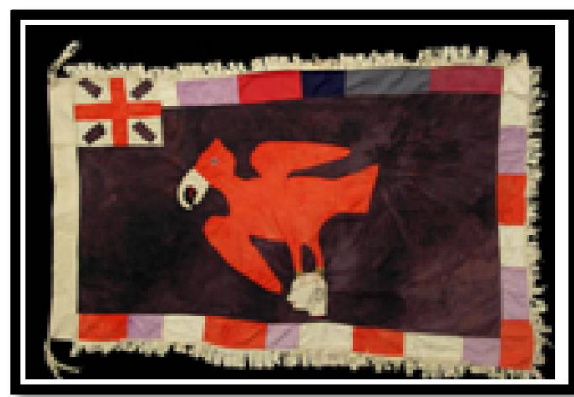

Figure 10: The Powerful Eagle

Eagles are powerful and smart creatures able to see in all directions, leaving no possible escape for the enemy. The eagle in the flag demonstrates the power and might of the company.

\subsection{Research Questions}

- To what extent can imagery in flags be used as a resource for textile designing.

- What character has imagery in Fante Asafo flags that qualify for textile designing.

\subsection{Research Objective}

This paper seeks to identify and examine indigenous knowledge systems(imagery) in Fante Asafo flags as an inspiration for textile design.

\section{Methodology}

The researchers employed the descriptive and artistic research approach. This enabled the researchers to critically study and give a thick expressive report of the culturally nested flag culture of the Fantes. The artistic research approach also afforded the researcher the extensive platform to create their artistic conceptions making them tangible for appreciation.

\subsection{Population}

The population for the study comprised the coastal dwellers from the coastal settlement across the central region of Ghana. The scope stretches from Senya Breku, Winneba, Saltpond and Cape Coast. The population selected presented a ware house of Fante Asafo flag art. Creativity, originality and uniqueness characterized the flag art of the selected coastal settlements.

The coastal dwellers presented a number of Asafo flags during their commemorative festival celebrations. But the researchers focused on flags with unique component fit for textile designing purposes and therefore sampled and selected ten (10) of such flags fit for the purpose of the study.

\subsection{Data Collection}

The researchers adopted interview and observation as means of collecting data for the study.

\section{$\underline{\text { 3.2.1. Interviews }}$}

The researchers adopted the interview approach to collect data on the flag culture of the Fantes. The one on one approach and the focus group discussions were adopted. The one on one gave the researchers the platform to have a closeup discussion with respondents. This was to have an in-depth knowledge of the historical and contextual inclination of the flag culture of the Fante people. It also helped us to value the flags as part of their material culture. This approach also helps some participants and groups to tell us stories of their valor and defeats with their flags in the Asafo culture. The focus group interviews also helped the researchers to validate the reliability of data collected. This is because data came from multiple sources. Group interaction was useful to clear confusing stories and perceptions on meanings of some complicated images. 


\subsubsection{Observation}

The researchers visited the field during their Asafo commemorative festival celebration to observe the activities of the Asafo companies. With the help of a digital camera, the flags and imagery within the flags were captured. These elements served as resource for textile designs processes. Observation processes were guided by established parameters by the researchers, these included; colour considerations in flags, symbols, imagery and general composition of elements in flags. These parameters were critical because they served as a guide for the researchers to focus on their main objective which is the Asafo flags and its components.

\subsection{Implication for Textile Design}

The Fante Asafo flags present varied imagery in its manifestation. The flag has lots of design components that can be disengaged to form individual stand-alone units that qualify to represent a motif in textile designing.

Yates (1995) notes that variety of designs may be typified by (a) motifs or subject matter (b) the style in which the motifs are rendered and (c) the arrangements or layout of motifs. He further states that these three elements combined with the colour look of the pattern, are the essentials that together forms a textile design. He categorises textile designs into four;

- Floral- A design with flowers or other plants as motifs, realistic and stylized.

- Conversational/Figurative - Designs that use pictures of recognisable objects making up the pattern for example cars, clowns, animals and other popular motifs.

- Geometrics - Designs derived from any geometric shape, realistic or stylized.

- Ethnic designs - Designs influenced by different cultures. Cultures contribute to motifs, patterns, and techniques popular in various styles. For example; African, Chinese, Japanese influence on motifs.

In reference to Yates viewpoint on ethnic designs, the Fante Asafo flag images are nested in a culture and influenced by the dictates and philosophies of the Fante culture.

Wisburn (2011) also shares an opinion that dovetails into the concept presented by Yates, he notes that ethnic designs are patterns drawn from a specific culture, having cultural significance or symbolism and celebrates some aspects of specific cultures history.

Meller and Elffers (2010) stress that ethnic patterns are folkloric and mostly conversational such as commemorative and specific to place and culture. Again, most images in ethnic oriented designs are seen as sign of pride in their heritage. Juxtaposing Meller and Elffers views with imagery in Fante Asafo flags it can be stressed that the imageries in flags are folkloric, conversational, commemorative as well, specific to the Fante culture and are signs of pride in the Fante heritage. So, by this standpoint the characteristics of the imageries qualifies as ethnic patterns worth to be used as inspiration for textile designing.

The imagery manifestation in the flags comes in concepts like overlapping, network of similar or different symbols interconnecting, intertwining, juxtapositions, superimpositions and possible superpositions of symbols. These image renditions radiate connotations, contextual meaning and fit for purpose.

But adapting the imageries as source of inspirations for textile designs, the creative designer will have to break the complex components down to the simplest units that will make it fit for application in the field of textile designing in areas of texturing and actual motif.

\subsubsection{The Artistic Processes}

The artistic processes involved the creative processes the researchers adopted in converting the flag imagery into the textile designs. It involved the use of the computer as a basic tool for copying, adaption and reproduction processes.

The Fante Asafo flags were adapted by the help of an art rendering software. Corel DRAW was adopted as a tool to help in the rendering. After rendering there was the need to break down components of the flags into simple units and symbols. A detailed colour separation was carried out in order to prepare specific screens for the multiple colours that are usual characteristic of the flags.

Before the designing commenced, the researchers scanned the flags onto the Computer using a scanner. The researchers carried out tracing by zooming an aspect of the picture and with the help of the rectangle tool trace the design after it had been imported onto the Corel DRAW working frame. Critical observation and analysis were made on the traced symbols and units because they served as the building blocks for the textile design in respect of motif and textures. Analysis was guided by kinds of symbols and motifs, colour, texture, lines and interconnected images, and appropriateness for textile designs. 


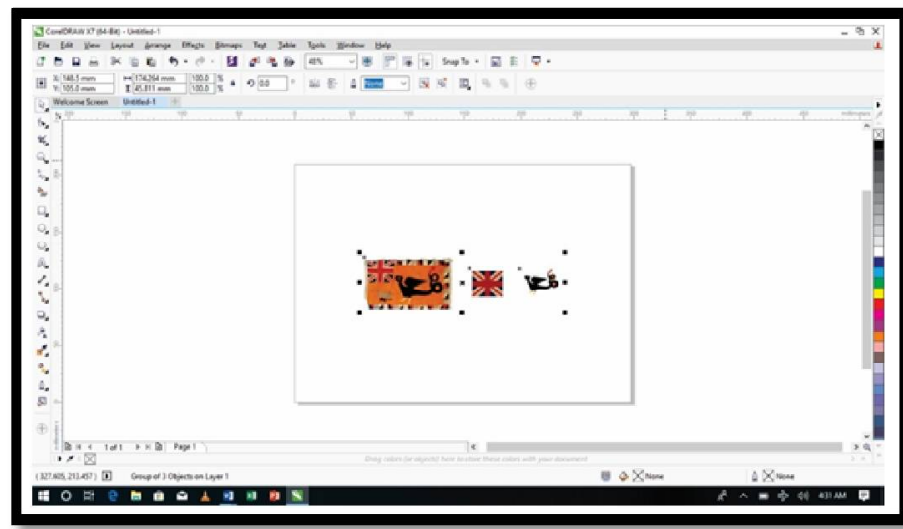

Figure 11: The Tracing and Separation of Units

The selected flags below followed the Corel DRAW rendering processes to achieve the

Needed outcome in order to be fit for use as motifs and textures for textile designing.

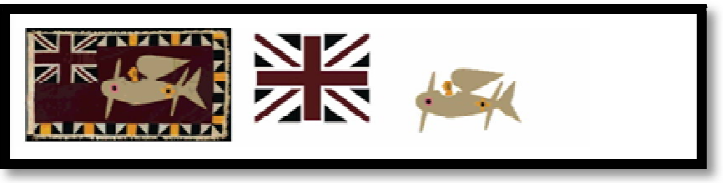

Figure: 12: Selected Components of the Flag

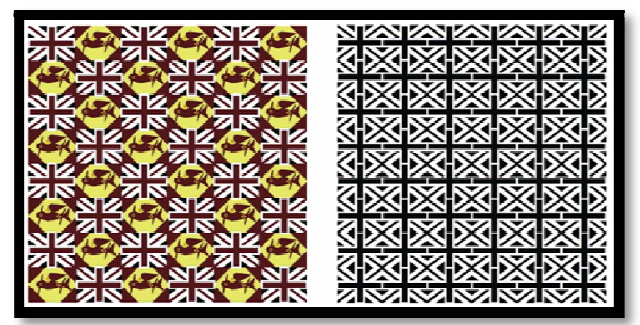

Figure13: Textile Designs Created from Fante Asafo Flag

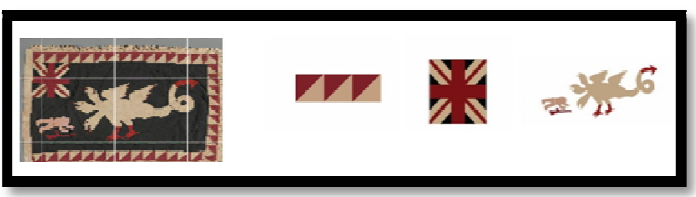

Figure 14: Selected Components of the Flag

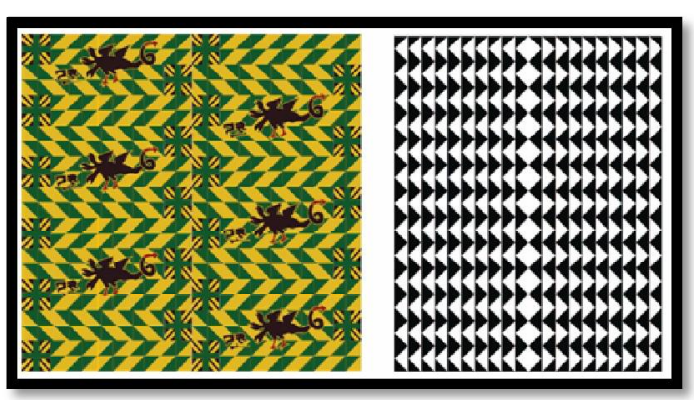

Figure 15: Textile Designs Created from Fante Asafo Flag

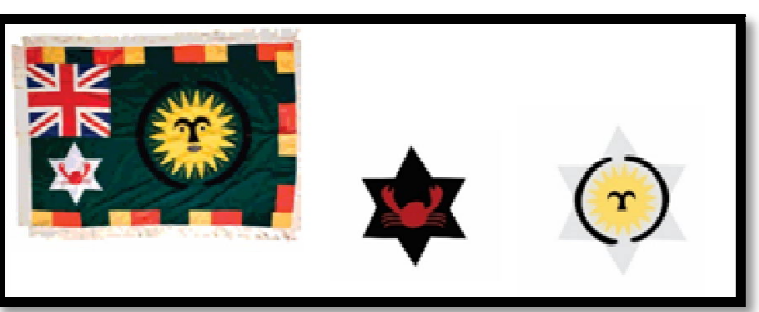

Figure 16: Selected Components of the Flag 


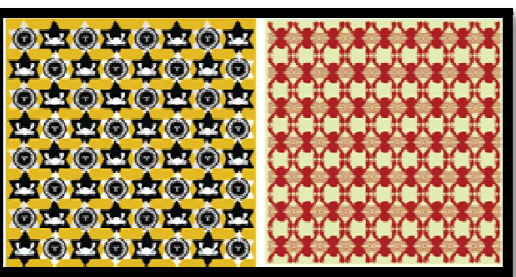

Figure17: Textile Designs Created from Fante Asafo Flag

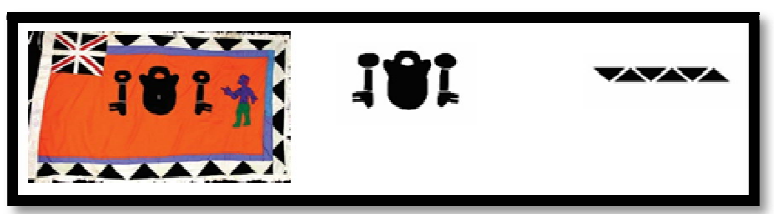

Figure 18: Selected Components of the Flag

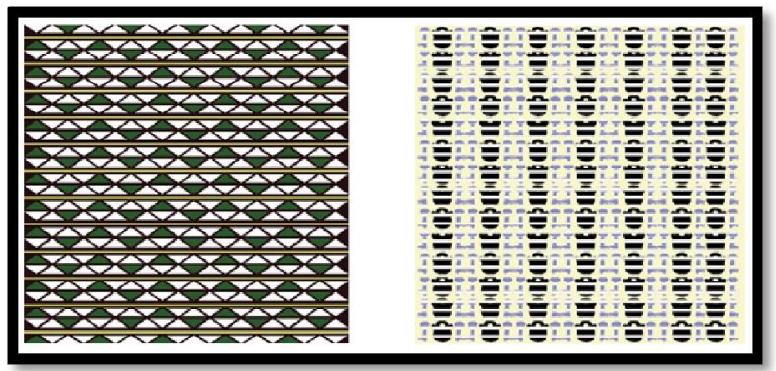

Figure19: Textile Designs Created from Fanteasafo Flag

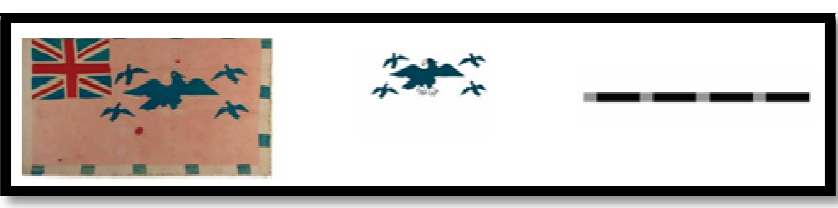

Figure 20: Selected Components of the Flag

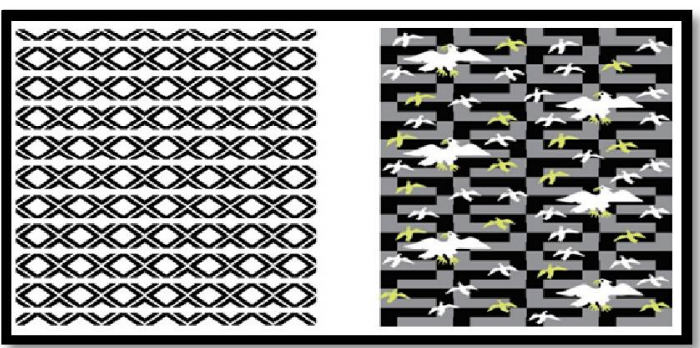

Figure 21: Textile Designs Created from Fante Asafo Flag

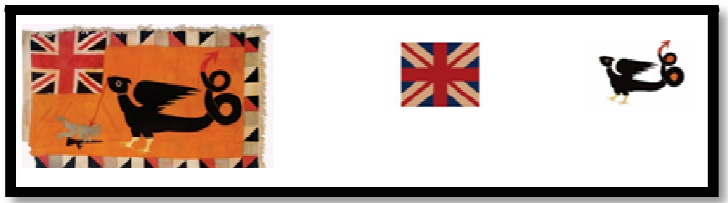

Figure 22: Selected Components of the Flag

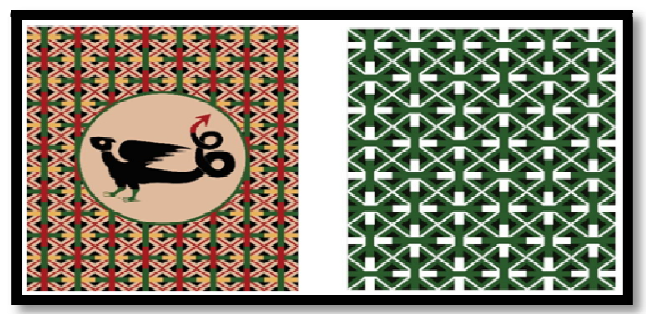

Figure 23: Textile Designs Created from Fante Asafo Flag 


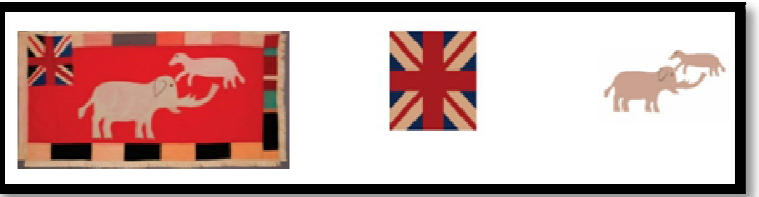

Figure 24: Selected Components of the Flag

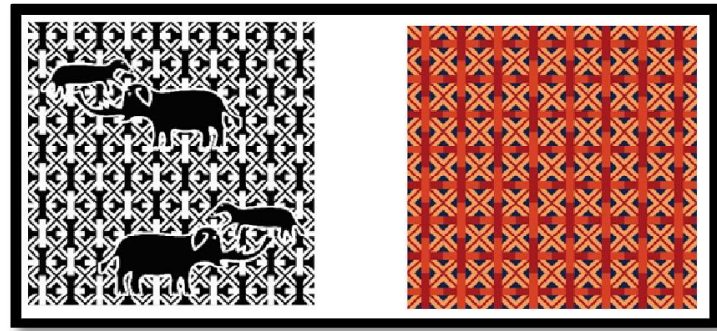

Figure 25: Textile Designs Created from Fante Asafo Flag

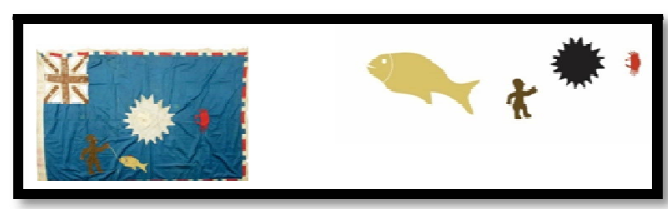

Figure 26: Selected Components of the Flag

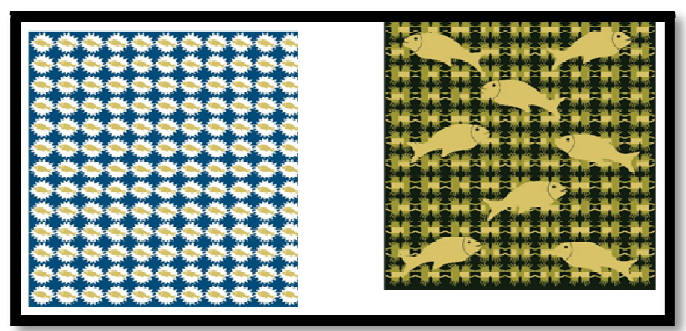

Figure 27: Textile Designs Created from Fante Asafo Flag

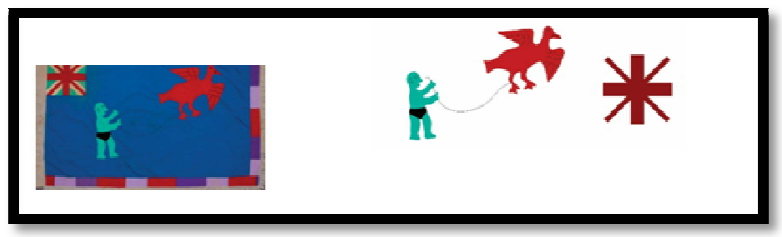

Figure 28: Selected Components of the Flag

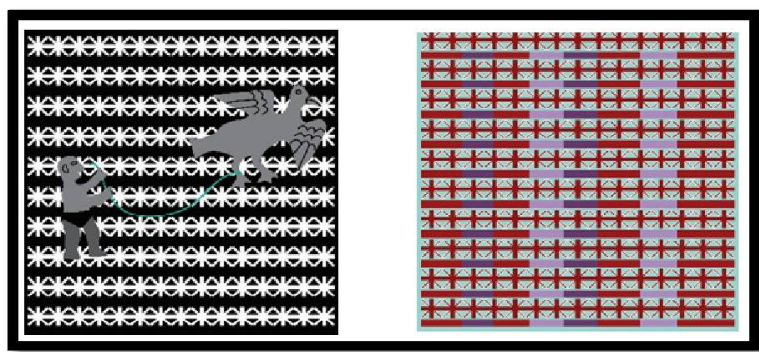

Figure 29: Textile Designs Created from Fante Asafo Flag

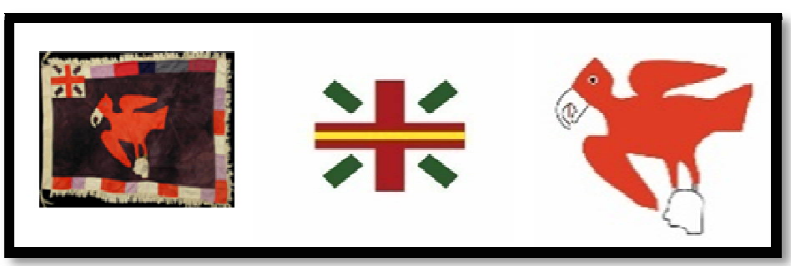

Figure 30: Selected Components of the Flag 


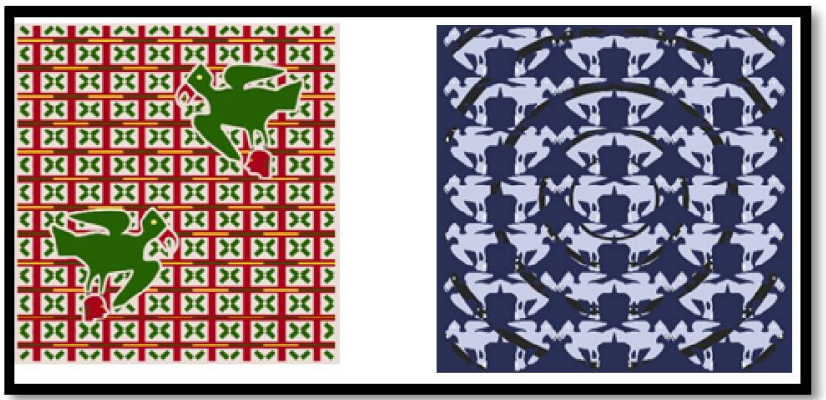

Figure 31: Textile Designs Created from Fante Asafo Flag

\section{Conclusion}

This paper sought to use the images and iconography in the Fanti Asafo flags as inspiration for textile design. Several designs were generated from the imagery in ten(10) selected Fante Asafo flags. The designs created were innovative and suitable for various purposes. The outcome of the designs had close resemblance to the original source of inspiration. The results of the study attest to the fact that, imagery in Asafo flags can be a source of inspiration for creating original and contemporary textile design concepts.

Steed and Stevenson (2012) talks about the importance of a textile designer to research and accumulate ideas from the world around to create new textile design concepts. Through research and innovation, the imagery in the Asafo flags which are powerful communication devices have been translated into interesting textile design concepts. The images were extracted from the flags and carefully manipulated using the coral draw software to innovate new textile design patterns fit for various purposes.

The selected Asafo flags adaptations create original and innovative textile designs for various end uses which can be used for purposes such as furnishing and home décor.

\section{References}

i. Ansu - Keremeh, K. (1998) Perspective on indigenous Communication in Africa, Dynamic and Future Dimensions, Gertmash Desktop publishing.

ii. Cole, H.M. (1989) Icons, deal and Power in the Art of Africa. Smithsonian Institution Press, Washington DC.

iii. Meller, S. and Elffer, J. (2010) Textile Designs. New York, Thames and Hudson. Picton, J. and Mack, J. (1993) African textile. London: British Museum Press. Thames and Hudson Ltd.

iv. Steed. J \& Stevenson. F. (2012). Basic textile design: sourcing ideas: researching colour, surface, structure, texture and pattern. London: A\&C Black Publishers.

v. Wisbrun, L. (2011). The complete guide to designing and printing fabrics, techniques, tutorials and inspiration from the innovative designer. London: A\&C Black Publishers Ltd.

vi. Yates, M. (1995). Textiles: a handbook for designers. London: W.W. Norton And Company. 